\title{
Herbal liposome for the topical delivery of ketoconazole for the effective treatment of seborrheic dermatitis
}

\author{
Vivek Dave $^{1} \cdot$ Swati Sharma $^{1} \cdot$ Renu Bala Yadav $^{1} \cdot$ Udita Agarwal $^{2}$
}

Received: 20 December 2016/Accepted: 9 November 2017/Published online: 21 November 2017

(C) The Author(s) 2017. This article is an open access publication

\begin{abstract}
The aim of the present study was to develop liposomal gel containing ketoconazole and neem extract for the treatment of seborrheic dermatitis in an effectual means. Azoles derivatives that are commonly used to prevent superficial fungal infections include triazole category like itraconazole. These drugs are available in the form of oral dosage that required a long period of time for treatment. Ketoconazole is available in the form of gel but is not used with any herbal extract. Neem (Azadirachta indica) leaves show a good anti-bacterial and anti-fungal activity and have great potential as a bioactive compound. The thin film hydration method was used to design an herbal liposomal preparation. The formulation was further subjected to their characterization as particle size, zeta potential, entrapment efficiency, \% cumulative drug release, and anti-fungal activity and it was also characterized by the mean of their physicochemical properties such as FTIR, SEM, DSC, TGA, and AFM. The results show that the formulation of liposomes with neem extract F12 were found to be optimum on the basis of entrapment efficiency in the range $88.9 \pm 0.7 \%$, with a desired mean particle size distribution of $141.6 \mathrm{~nm}$ and zeta potential $-45 \mathrm{mV}$. The anti-fungal activity of liposomal formulation F12 was carried out against Aspergillus niger and Candida tropicalis by measuring the inhibition zone 8.9 and $10.2 \mathrm{~mm}$, respectively. Stability of optimized formulation was best seen at refrigerated condition. Overall,
\end{abstract}

Vivek Dave

vivekdave1984@gmail.com

1 Department of Pharmacy, Banasthali University, Banasthali, Rajasthan 304022, India

2 Sagar Institute of Research and Technology-Pharmacy, Bhopal 462041, India these results indicated that developed liposomal gel of ketoconazole with neem extract could have great potential for seborrheic dermatitis and showed synergetic effect for the treatment.

Keywords Ketoconazole $\cdot$ Neem extract $\cdot$ Seborrheic dermatitis · Liposomal gel · Anti-fungal activity

\section{Introduction}

The advancement of topical therapy in the practice of dermatology has increased dramatically in the past decades. Major developments have been made in these years to improve the quality and efficacy, and many new products are now available in markets, such as lotions, gels, ointments and sprays. It has been considered as a better drug-delivery system that allows therapeutic action of active ingredients avoiding systemic absorption (Vyas and Khar 2007; Sharma 1997; Bangham and Horne 1964). Presently, many drugs are available that provide an excellent therapeutic activity by maintaining skin moisture microbial count and surface colonization of microbes, when given in infectious conditions. Azoles derivatives are commonly used to prevent superficial fungal infections which includes triazole categories such as itraconazole and voriconazole. These drugs are available in the form of oral dosage that requires a long period of time for treatment. Ketoconazole, that is also an azole derivative is available in market in the form of gel, however, any research for ketaconazole with natural extract of plant and herb has not been made been thoroughly (Rosenkrantz et al. 2006; Aggarwal and Shinshu 2012; Anand et al. 2010).

Neem (Azadirachta indica) leaves show a good antibacterial and anti-fungal activity which is already reported 
in many ancient literature and which possess great potential as a bioactive compound for many diseases. Neem has been used from the ancient period of time for many tropical, bacterial and fungal diseases (Singh et al. 2014). For this study, the neem leaf extract was taken in consideration due to their earlier findings, and to enhance the treatment value of ketoconazole, as well as to provide a natural boost for treatment, and the population acceptability of herbal products has increased due to the awareness of the use of herbal products and their benefits. Anti-fungal studies were done by well diffusion method and turbidimetry method against Aspergillus niger and Candida tropicalis. Media was prepared in accordance to the fungal species and the zone of inhibition and dry weight were measured.

Seborrheic dermatitis is an inflammation of the upper layer of the skin that causes scales on the scalp, face and other parts of the body, when this affects newborns; it is called as cradle cap. The inflammation starts to gradually increase and scales up as a whitish fungal layer over the skin. In adults, it often appears as a condition of the scalp, itching, burning, or hair loss may occur. This may also affect the ear, eyebrows, and bridges of nose, around the nose or the trunk. Fungal dermatitis is weather-dependent and gets worse in extreme conditions such as winters and summers due to dryness and sweating, respectively. But there are many way to control the problem, such as medicated shampoos, lotions, creams containing selenium sulfide, pyrithione, zinc, sulphur and salicylic acid are available in the market. Effect of drugs also depends upon their route of administration, drug delivery pattern; hence we need a better drug-delivery system which enables us to reach the goal easily. In the present scenario, a raise is seen in the targeted action, sustained release, and controlled release. Among so many delivery systems, nanocarriers, lipoproteins, microspheres, and nanosomes are in big consideration and are practiced very often. Here, in such delivery systems, active ingredients are transported by some carrier moiety to the targeted place. It helps in avoiding toxicity, interaction, increasing therapeutic action and improving kinetics (Lasic 1990; Uchegbu and Vyas 1998). In this study, concluding the basic demand of Seborrheic dermatitis, we have designed a novel vesicular system of ketoconazole with the herbal plant extract of Azadirachta indica, which has a history of fighting with many dermal diseases. The use of plant extract has been suggested to increase the therapeutic efficacy, due to their synergistic effect with ketoconazole because the target disease (Seborrheic dermatitis) does not easily go off once it starts to scale up in any part of the scalp, eyes, ear, etc., and especially in the case of pediatrics. That is why we need to hypothesize a kind of drug-delivery system which shows their maximum therapeutic efficacy with least side effects, and second, we also know that the delivery of drug with regular base of ointment is least effective than any other novel vesicular system because this kind of therapeutic preparation also controls the delivery of drug at the targeted site.

\section{Experimental}

Ketoconazole was purchased from Sigma-Aldrich Chemical, USA. Soya lecithin and cholesterol were purchased from Hi media laboratory, Mumbai, India. Distilled water (HPLC grade) was purchased from Merck specialties Pvt. Ltd., Mumbai, India. All the other chemicals used were of analytical grade. Neem leaves were collected from the Medicinal garden of Banasthali University.

\section{Preparation of neem extract}

$150 \mathrm{gm}$ of neem leaves were taken and reduced to half its size, and $400 \mathrm{ml}$ ethanol was added to it in a conical flask and was covered with paraffin film. It was then allowed to stand at room temperature for $48 \mathrm{~h}$ and then was filtered to obtain ethanol extract. Ethanol was then evaporated with the help of rota-evaporator at $150 \mathrm{RPM}$ and $55^{\circ} \mathrm{C}$ temperature (Azmin et al. 1985).

\section{Preparation of liposomes}

The thin-film hydration technique discussed by Bangham opted for the preparation of liposomes. Soya lecithin and cholesterol were used as lipid and stearic acid, and sorbitol were used as permeation enhancer. For the preparation of liposomes, accurately weighed soya lecithin in different amounts as shown in Table 1 was dissolved in chloroform and stirred using a magnetic stirrer (Remi Motors Ltd., Mumbai). Aqueous drug solution that contained sorbitol/ stearic acid was then mixed, followed by the addition of cholesterol. A milky suspension formed and was stirred well to mix it properly. This mixture was then sonicated for a cycle of 10 min using Probe sonicator (PCi analytical). Suspension was now taken in a round-bottom flask and attached to rota-evaporator (Heidolph Germany). The rotaevaporator water bath temperature was set at $45^{\circ} \mathrm{C}$, with a rotation speed of $120 \mathrm{rpm}$. During film formation, the organic solvent was evaporated under reduced pressure, so that a clear thin film of uniform thickness could form. When the thin film of the subjected material was formed, the existing pressure inside the RBF was reduced, and then the RBF was kept into a desiccator chamber overnight for complete removal of trace organic solvent. When the thin film of the liposome completely dried, it was hydrated with $5 \mathrm{ml}$ of phosphate buffer $\mathrm{pH} 6.8$ and stirred vigorously to form small vesicles of liposomes. This mixture was then 
Table 1 Composition table of the formulations

\begin{tabular}{|c|c|c|c|c|c|c|c|c|c|c|c|c|c|c|c|c|}
\hline Composition & F1 & $\mathrm{F} 2$ & F3 & $\mathrm{F} 4$ & F5 & F6 & F7 & F8 & F9 & F10 & F11 & $\mathrm{F} 12$ & F13 & $\mathrm{F} 14$ & F15 & F16 \\
\hline Drug (mg) & 50 & 50 & 50 & 50 & 50 & 50 & 50 & 50 & 50 & 50 & 50 & 50 & 50 & 50 & 50 & 50 \\
\hline Neem extract (mg) & - & - & - & - & - & - & 50 & 50 & 50 & 50 & 50 & 50 & 50 & 50 & 50 & 50 \\
\hline Soya lecithin (gm) & 1 & 2 & 3 & 1 & 2 & 3 & 1 & 2 & 3 & 1 & 2 & 3 & 3 & 3 & 3 & 3 \\
\hline Cholesterol (mg) & 100 & 150 & 200 & 100 & 150 & 200 & 100 & 150 & 200 & 100 & 150 & 200 & 200 & 200 & 200 & 200 \\
\hline Steric acid (mg) & - & - & - & 50 & 50 & 50 & - & - & - & 50 & 50 & 50 & 25 & 50 & 25 & \\
\hline Sorbitol (mg) & 50 & 50 & 50 & - & - & - & 50 & 50 & 50 & - & - & - & 25 & 50 & & 25 \\
\hline Chloroform (ml) & 10 & 10 & 10 & 10 & 10 & 10 & 10 & 10 & 10 & 10 & 10 & 10 & 10 & 10 & 10 & 10 \\
\hline Phosphate buffer $6.8(\mathrm{ml})$ & 20 & 20 & 20 & 20 & 20 & 20 & 20 & 20 & 20 & 20 & 20 & 20 & 20 & 20 & 20 & 20 \\
\hline
\end{tabular}

again subjected to sonication for two cycles of $10 \mathrm{~min}$ each to reduce particle size. Liposome thus prepared was stored in vials in the refrigerator and allowed to swell for at least 24 h (Rai et al. 2012; Ainbinder and Touitou 2005).

\section{Incorporation of prepared liposomes into carbopol gel}

Carbopol $934 \mathrm{~K} \mathrm{1 \%}$ w/v was soaked in a minimum amount of water for an hour. The swelled mass of carbopol was stirred till carbopol completely dissolved in the distilled water. Prepared liposome suspension $(6 \mathrm{ml})$ containing ketoconazole and neem extract $(100 \mathrm{mg})$ was added to carbopol solution on continuous stirring at $700 \mathrm{rpm}$ at $30{ }^{\circ} \mathrm{C}$ until uniform liposomal gel was formed. $\mathrm{pH}$ was then adjusted to 7.4 by tri-ethanol amine. Glycerin was added to the formed liposomal gel which serves as a humectant which enhances skin hydration, thus increases drug penetration through skin. The liposomal gel was left equilibrating for $24 \mathrm{~h}$ at room temperature $\left(25 \pm 1{ }^{\circ} \mathrm{C}\right)$ (Anand et al. 2010).

\section{Attenuated total reflection-Fourier transform infrared spectroscopy (FTIR)}

Infrared spectra of liposomes loaded with ketoconazole, neem, soya lecithin, cholesterol, stearic acid, and sorbitol were analyzed using a ATR-FTIR spectra at room temperature by Bruker EQUINOX 55 FTIR spectrophotometer equipped with a liquid nitrogen cooled mercury cadmium telluride (MCT) detector at a nominal resolution of $2 \mathrm{~cm}^{-1}$. The internal reflection element (IRE) was a diamond, with an incidence angle of $45^{\circ}$, scans 32, 21 resolutions leading to one internal reflection. An advanced ATR correction was applied to all spectra, and the region from 4000 to $400 \mathrm{~cm}^{-1}$ was peak fit using Opus software (Yub Harun et al. 2014; Shah and Misra 2004).

\section{Differential scanning calorimetry (DSC) analysis}

Differential scanning calorimetry (DSC) experiments were performed with NETEZCH DSC 204 F1 phoenix differential scanning calorimeter chamber. The instrument comprised a calorimeter, a flow controller, a thermal analyzer, and an operating software. Samples of pure ketoconazole, polymers, and mixtures, the lyophilized liposomal sample, polymers, and gels were weighed in an aluminum pan and sealed with an aluminum lid. The pan was placed in the DSC and heated from 20 to $350{ }^{\circ} \mathrm{C}$ at a heating rate of $50{ }^{\circ} \mathrm{C} / \mathrm{min}$ in a nitrogen atmosphere. The scan was recorded and plotted, showing heat flow (w/g) on the $\mathrm{y}$-axis and temperature on the $\mathrm{X}$-axis (Yub Harun et al. 2014; Shah and Misra 2004; Vyas and Khar 2007).

\section{Thermo gravimetric analysis (TGA)}

In this study, TGA was used to study the thermal behavior of drug, polymers and lyophilized formulation. This study was done to determine the physical and chemical properties with the help of PROTEUS thermal analysis. TGA also gives us an idea about weight loss, vaporization, sublimation, absorption, adsorption, etc. TGA is generally used to conclude selected characteristics of samples that show either weight loss or gain due to decomposition. Samples were taken in a crucible and after tearing, the weight crucible was kept back and assembly was made to run and the thermogravimetric graph was recorded (Alexopoulouet et al. 2006).

\section{Scanning electronic microscopy (SEM)}

In this study, SEM was used to determine the surface morphology of the optimized formulation. This study was performed using scanning electron microscope SEM (EVO 18, Zeiss, Germany). Prior to analysis, lyophilized liposomal formulation was fixed using a double-sided carbon 
adhesive tape by placing on copper stubs, and gold sputtering was done, then analyzed at different magnifications (Benoy et al. 2009).

\section{Atomic force microscopy (AFM)}

In this study, atomic force microscope (AFM) was carried out on AIST-NT (model no. SmartSPM 1000). The images of the optimized liposomes were captured in AC mode and imaging tip used for the liposomes is AIST FP Tip no. 01. The software used for the capturing of the images is AISTNT SPM Control software and mica slips were used to prepare the AFM slides for liposomal suspension. Approx. $10 \mu 1$ liposomal suspension was dropped onto the mica slip and then a thin coating was formed using spin coater dryer machine. The thickness of slide was adjusted manually by dropping more or less suspension consequently. The prepared slide was kept under the lens and analyzed at different magnifications and three-dimensional structures were observed.

\section{Particle size analysis and zeta potential}

The liposomal vesicle size and zeta potential of optimized liposome suspension was determined by dynamic light scattering (DLS) using a Malvern Zeta master UK. Liposomes were dispersed in Millipore water and system was set at an angle of $90^{\circ}$ at $25^{\circ} \mathrm{C}$, a medium with viscosity of 0.8872 and a refractive index of 1.330 . The particle size distribution was characterized using PDI, which determines the width of size distribution. Zeta potential was determined using Malvern Zetasizer Nano ZS (Malvern Instruments, UK), performed using a combination of laser Doppler velocimetry and phase analysis light scattering (PALS) (Dmitry et al. 2009; Divakar et al. 2013). All the measurements were taken in triplicate (Yub Harun et al. 2014; Shah and Misra 2004; Vyas and Khar 2007).

\section{Entrapment efficiency}

The amount of drug entrapped is calculated by deducting the amount of un-entrapped drug by the amount of total drug added initially. Entrapment capacity of ketoconazole and neem-loaded liposomal suspension was determined by ultracentrifuge (Remi) equipped with a TLA-45 rotor at $15,000 \mathrm{rpm}$ at $4{ }^{\circ} \mathrm{C}$ for $3 \mathrm{~h}$. After separation of ketoconazole and neem extract entrapped liposome vesicles, the amount of un-entrapped was determined using UV/Visspectrophotometry at $245 \mathrm{~nm}$. Each sample was analyzed in triplicate (Bhandari and Kaur 2013; Beeravelli et al. 2016; Betageri and Parsons 1992; Mohammed Haneefa et al. 2014). The amount of drug entrapped in vesicles was calculated by the equation given below:
Entrapment efficiency $\%=\frac{\text { amount of free drug }}{\text { total amount of drug }} \times 100$.

\section{Extrudability}

The developed liposomal gel was packed in a closed collapsible tube containing $20 \mathrm{gm}$ of gel and then firmly pressed. Rollback was prevented using clamp. The cap was removed and gel extruded until the pressure was degenerated (Panigrahi et al. 2006; Srisombat et al. 2005; Dave et al. 2010; Hathout et al. 2007).

\section{Spreadability}

In this study, spreadability was calculated by taking two glass slides having $7.8 \mathrm{~cm}$ length and then the prepared liposomes were sandwiched in-between them. Then a weight of $50 \mathrm{gm}$ was placed over the upper slide of glass for uniform spreading of the liposomal gel and the takeoff that applied weight of $50 \mathrm{mg}$, and then the spreadability of the gel was measured with respect to a known applied weight of $20 \mathrm{gm}$ with the help of a pulley, and the time taken to roll down the glass slide was noted. Subsequently, the procedure was repeated thrice to take an average of the total spreadability achieved by placing $20 \mathrm{gm}$ of weight over it.

Further, spreadability was calculated by the following formula:

$S=M \times L / T$,

where $S$ is the spreadability of the liposomal gel, $M$ is the weight tied on the upper slide $(20 \mathrm{gm}), L$ is the length of the slide $(7.8 \mathrm{~cm})$ and $t$ is the time taken by the upper slide to roll down (Momo et al. 2005).

\section{Viscosity}

Viscosity of liposomal gel was measured using the Brookfield Viscometer model LVDV II Pro. Viscosity was measured at room temperature by rotating the spindle $\mathrm{S} 96$ at 10, 15 and $20 \mathrm{rpm}$. Liposomal gel was taken in beaker and spindle was dipped in it. The reading was measured at upper, middle and lower case at different intervals (Lopes et al. 2004; Dave et al. 2010).

\section{In vitro drug release}

The in vitro drug release study of herbal liposome gel was studied on the cellulose acetate membrane which was soaked in phosphate buffer $\mathrm{pH} 6.8$ for $24 \mathrm{~h}$ prior to work, so that it can easily tie to diffusion tube. Diffusion tube was clamped and dipped in phosphate buffer 6.8 in beaker. It was kept at $37^{\circ} \mathrm{C}$ of phosphate buffer 6.8 and $1 \mathrm{gm}$ of 
herbal liposomal gel was added in donor compartment of the diffusion tube, followed by parafilm covering to avoid evaporation of the solvent system. The phosphate buffer 7.4 was kept in receiver compartment and stirred continuously at $500 \mathrm{rpm}$. From the receptor compartment, $3 \mathrm{ml}$ solution was withdrawn at $0,1,2 \ldots 8, \ldots 0.12 \mathrm{~h}$, respectively, at a particular time interval and replaced by buffer solution, so that volume of receptor solution was kept constant during drug release (Anand et al. 2010; Dodov et al. 2004). The drug concentrations in the withdrawn samples were determined at $245 \mathrm{~nm}$ against appropriate blank. The in vitro drug release was carried out in triplicate for each preparation and expressed as Mean \pm SD., and then the cumulative drug release (\%CDR) was calculated and a plot of time versus \%CDR was constructed and shown graphically. In vitro skin permeation studies were conducted for all liposome formulations and reported (Panigrahi et al. 2006; Sezer et al. 2004; Agarwal et al. 2014).

\section{Stability studies}

Stability studies were performed for herbal liposomal suspension to investigate any loss of drug from liposomes and effect of stability during storage condition. From the study, optimized formulation of F12 herbal liposome formulation was subjected to accelerated stability studies as per ICH guidelines (34). Optimized formulation was kept in vial and stored at refrigerator temperature $\left(4^{\circ} \mathrm{C} /\right.$ $60 \pm 5 \% \mathrm{RH})$, room temperature $\left(25^{\circ} \mathrm{C} / 60 \pm 5 \% \mathrm{RH}\right)$ and ambient temperature $\left(40{ }^{\circ} \mathrm{C} / 75 \pm 5 \% \mathrm{RH}\right)$. After 15 days, 1 , and 3 months drug remaining in liposomes was again determined using centrifugation and the same method was opted as that of entrapment efficiency, PDI, zeta potential, spreadability, extrudability, $\mathrm{pH}$, viscosity, cumulative release to check the effect of temperature on the preparation (Agarwal et al. 2014; Shah et al. 2014; ICH 2003).

\section{Anti-microbial susceptibility test of neem extract}

The microbiological assay of neem extract was performed to maintain the quality parameters of the neem extract by visualizing any visible growth on the nutrient agar plate employing cup-plate method. The nutrient agar media $(2.8 \% \mathrm{w} / \mathrm{v})$ were prepared and sterilized at $121{ }^{\circ} \mathrm{C}$ for $21 \mathrm{~min}$ at $15 \mathrm{lbs}$. pressure and poured into sterile Petri plates. Media were allowed to solidify and then loop full bacteria was inoculated (Staphylococcus aureus and E. coli from grown bacterial suspension) with the help of swapping method followed by boring in the plate $(9 \mathrm{~cm}$ in diameter and $5 \mathrm{~cm}$ in thickness) with the help of cork-borer to obtain definite size of hole. Standard drug (for positive quality control) and neem extract equivalent to 2, 4, 6, and $8 \mu \mathrm{g} / \mathrm{ml}$ of drug was poured in the hole with crystal violet dye and incubated for $24 \mathrm{~h}$ at $37^{\circ} \mathrm{C}$. Further, the zone of inhibition was measured using Vernier caliper in $\mathrm{mm}$ and anti-microbial effect was compared with the standard drug. The entire operation except the incubation was carried out in a laminar airflow unit (Syarifah and Izham bin 2014).

\section{Anti-fungal studies}

Anti-fungal studies were done by preparing media and broth as per the fungal species. Aspergillus niger (MTCC 8652) and Candida tropicalis (MTCC 9038) strain were taken. Strains were already available in revived condition, and then media were prepared and autoclaved for $20 \mathrm{~min}$ at $121{ }^{\circ} \mathrm{C}$. The sterilized media were then allowed to come down up to $\sim 45$ to $50{ }^{\circ} \mathrm{C}$ and poured into different Petri dishes or tubes. Further, media were allowed to solidify, and culture strain was added by spreading it over the surface of solidified media $(0.1 \mathrm{ml}$ will be poured by micro pipette \& Spread by L-tube). About three wells in each plate of $6 \mathrm{~mm}$ diameter were punched in agar surface with the help of sterilized cork or borer for placing the formulation. Petri dishes were incubated for $72-96 \mathrm{~h}$ at $30{ }^{\circ} \mathrm{C}$. Incubated Petri dishes were observed and zone of inhibition was then measured and compared with standard formulation. In case of broth, it was too autoclaved for $20 \mathrm{~min}$ at $121{ }^{\circ} \mathrm{C}$. It was then allowed to come down up to $\sim 45-50{ }^{\circ} \mathrm{C}$ and poured into different cultural tubes. Fungal strain was then added followed by the addition of formulation ( $0.1 \mathrm{ml}$ will be poured by micro pipette) and these cultural tubes were than incubated for $72-96 \mathrm{~h}$ at $30{ }^{\circ} \mathrm{C}$, and checked for dry weight and compared with standard (Syarifah and Izham bin 2014).

\section{Results and discussion}

\section{Fourier transform infrared (FTIR) spectroscopy}

Fourier transform infrared (FTIR) spectroscopy studies are helpful to check possible interaction between drugs and excipients. IR spectra of pure drug (ketoconazole) and formulation containing drug and all the excipients that include phospholipids, permeation enhancer are shown in Fig. 1. Pure drug has shown its major peaks at wave numbers 3828.06, 2361.20, 1641.39, 1743.48, $1508.52 \mathrm{~cm}^{-1}$ (presence of aromatic ring and multiple bonds), $1450.52 \mathrm{~cm}^{-1}$ (O-C--O of acid), $1286.73 \mathrm{~cm}^{-1}$ (multiple bond stretching), $812.65 \mathrm{~cm}^{-1}$ (meta distribution of aromatic protons), $729.09 \mathrm{~cm}^{-1}(\mathrm{C}-\mathrm{H}$ bend) and $629.20 \mathrm{~cm}^{-1}$, whereas peaks of lipids were found at the wave number obtained 3274.72, 2359.55, 1644.16, $1224.74 \mathrm{~cm}^{-1}$. Prepared formulations were also scanned for the same region and found peaks almost in the very 
Fig. 1 FTIR spectra of a drug, b soya lecithin, c cholesterol, d stearic acid and e optimized formulation F12

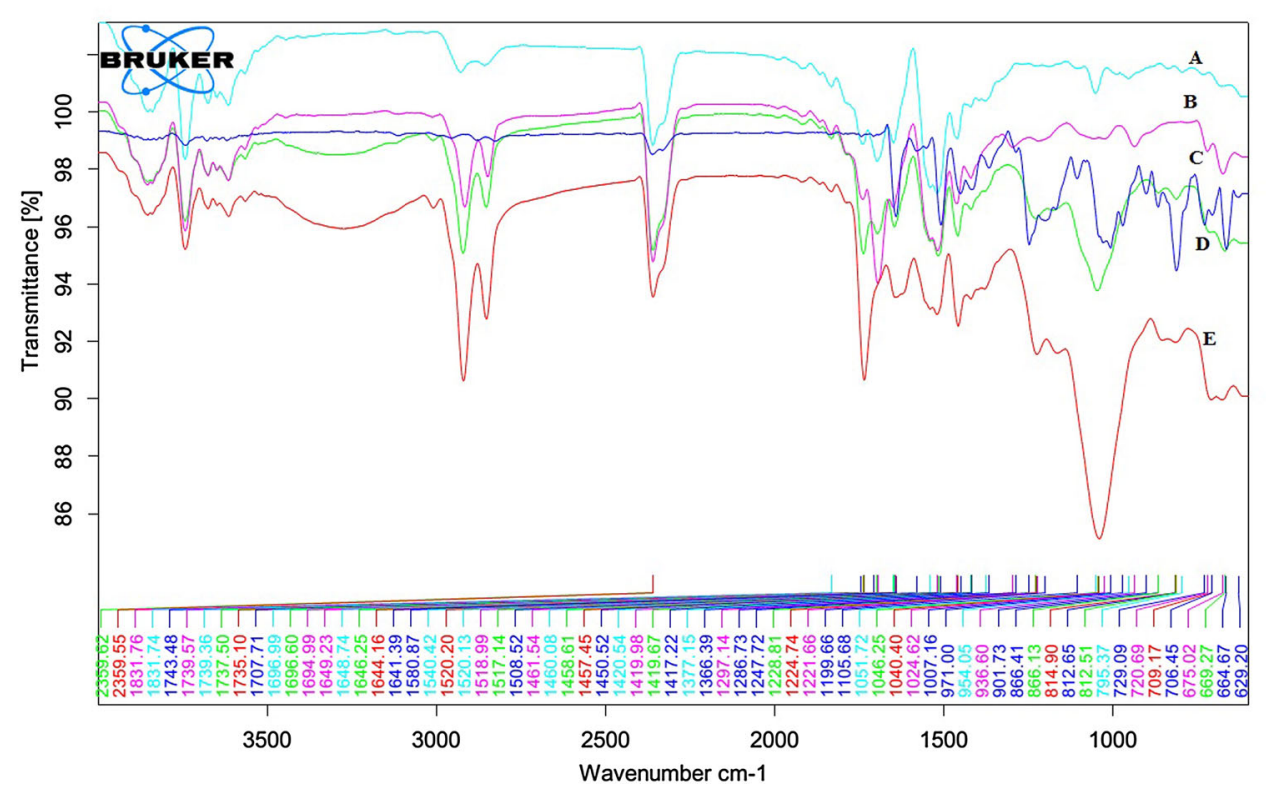

close range and any possible interaction between lipid and drug was not found, which means that the polymer and drug are compatible with each other. The peaks of formulation F12 were found to be very closer to the peaks of pure ketoconazole, i.e., 3321.95, 2360.39, 2117.21, $1638.73 \mathrm{~cm}^{-1}$, the result revealed that there was no considerable change in the IR peaks of ketoconazole and optimized formulation, indicating the absence of any interaction between the drug and polymer.

\section{Differential scanning calorimetry (DSC) analysis}

The results of differential scanning calorimetry (DSC) studies are depicted in Fig. 2. Pure ketoconazole has shown a sharp endothermic peak at $154.92{ }^{\circ} \mathrm{C}$ corresponding to its melting point. Melting point of cholesterol, soya lecithin, sorbitol and stearic acid were observed at 144.67, 87.84, and $106.58,63.58{ }^{\circ} \mathrm{C}$. The peaks of optimized formulation F12 were found to be $193{ }^{\circ} \mathrm{C}$, with low intensity and broad endothermic peaks compared to the pure drug. This indicates that when the drug is incorporated into the liposomes, it forms a bilayer along with the other lipids which decreases their crystallinity and becomes more amorphous in nature, which leads to the formation of a new phase which shows shifting and broadening of the drug peak towards higher temperature, and thus shows their increase in stability after incorporating the drug into the liposomal core. Thus, this study indicates that the F12 was an
Fig. 2 DSC thermogram of a ketoconazole, b soya lecithin and $\mathbf{c}$ optimized formulation F12

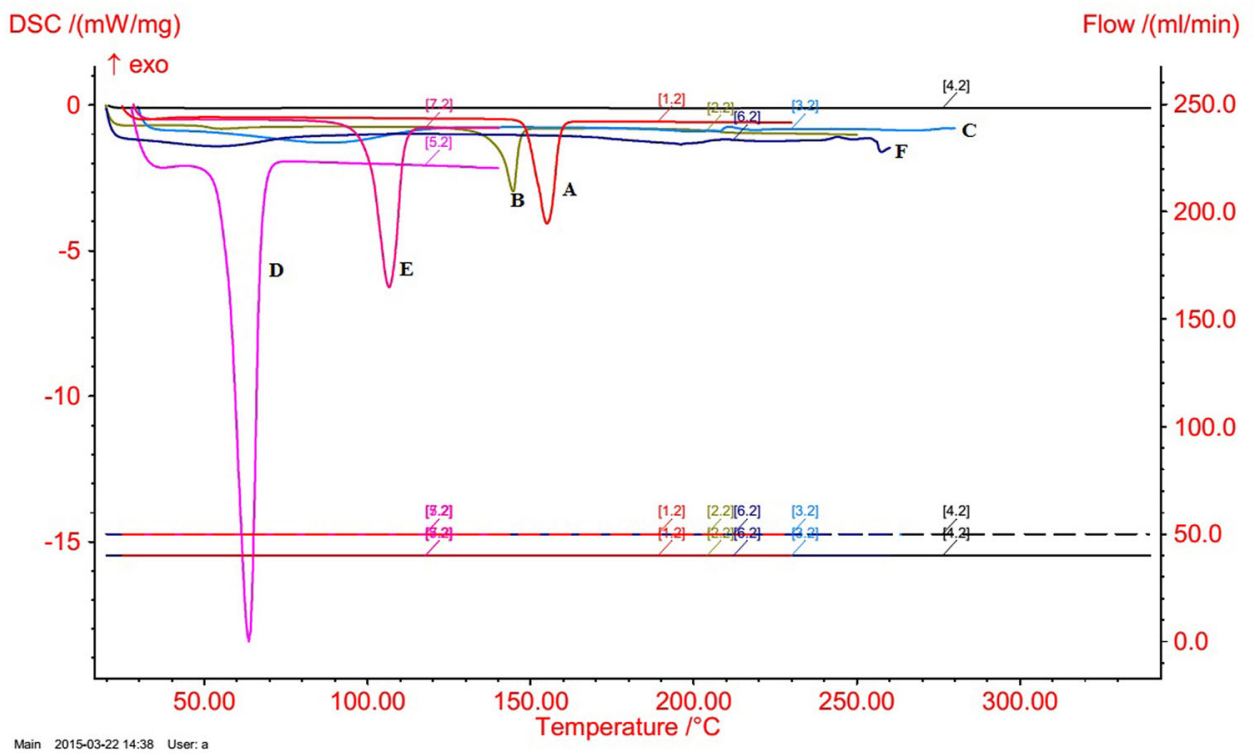


optimized formulation along with the labeled amount of ingredients.

\section{Thermogravimetric analysis (TGA)}

In this analysis, the optimized formulation F12 and other ingredients were subjected to a controlled temperature program in a controlled atmosphere. The combined TGA graph is shown in Fig. 3, and the TGA graph of pure drug showed that the mass remained constant with increasing temperature, but as it approached melting point of drug, it started to fall down. Similar phenomenon was also observed with the formulated herbal liposome formulation F12, which showed a sharp falling of the curve at $175^{\circ} \mathrm{C}$, which reveals that the combination of lipid with the drug enhances its stability. Another TGA study was done for soya lecithin and cholesterol alone and it showed sharp falling curves at 180 and $190{ }^{\circ} \mathrm{C}$, respectively. All these findings revealed that excipients or moisture content have no adverse effect on formulations.

\section{Scanning electronic microscopy (SEM)}

The surface morphological studies determined by SEM revealed that the liposomes obtained have a smooth surface and were spherical in nature in the optimized formulation. The SEM image of the optimized formulation is shown in Fig. 4. The SEM image of the prepared liposomes was taken at different resolutions as at $\times 6500$ and $\times 6,500$. In both the images, the liposomal formulation was shown spherical in shape having smooth surfaces, showing the particle size ranging from $2 \mu \mathrm{m}$ to $200 \mu \mathrm{m}$. At resolution $\mathrm{x} 6,500$, the particle of the formulation has been shown in the cluster form, this may happen due to lyophilization of the liposomes which leads to loss in their structural integrity. The particle size, on increasing the resolution, defines the surface but due to particles aggromolation with each other the differentiation of particle was not possible.
To overcome this problem, an advanced technique such as AFM was employed which is described in the next section.

\section{Atomic force microscopy (AFM)}

AFM surface topographic imaging is an advanced imaging technology that can exactly passion the height, diameter and other surface properties of the formulation that cannot be easily studied using SEM and TEM. The AFM surface topographical imaging gives the idea about swelling dynamics of the ingredients with each other and their actual behavior, all these can be visualized with the help of AFM in a high resolution. The AFM topographical imaging of the optimized formulations is depicted in Fig. 4. The figure clearly shows that the formulation height and the diameter are in appropriate range. The surface topography of liposomes show a height of 6.5-7.0 $\mathrm{nm}$ and an average surface area of 200-400 $\mathrm{nm}$. In the second image of the AFM, it was clearly shown that after some time of deposition of the liposome when the topographical imaging was taken again, it shows a flattening structure of the liposomes and slight decrease in height; this is a basic tendency of liposomes reported in various articles. AFM surface topographical imaging.

\section{Particle size and zeta potential analysis}

The particle size and polydispersity index (PDI) were determined using dynamic light scattering technique and are shown in Table 2 The prepared formulation from F1F16 shows the mean particle sizes ranging from $141.6 \pm 1.8$ to $237 \pm 1.9 \mathrm{~nm}$, PDIs ranging from $0.245 \pm 0.54$ to $0.488 \pm 0.65$ and zeta potential ranging from $-45 \pm 0.8$ to $-75 \pm 0.5 \mathrm{mV}$. Formulations F1-F3 with increasing soya lecithin and cholesterol concentration and a constant sorbitol concentration showed mean particle sizes of $188 \pm 1.2$ to $198 \pm 1.0 \mathrm{~nm}$ with PDI of $0.284 \pm 0.62$ to $0.383 \pm 0.64$, and zeta potential ranging from $-48 \pm 0.6$ to $-62 \pm 0.7 \mathrm{mV}$, respectively.

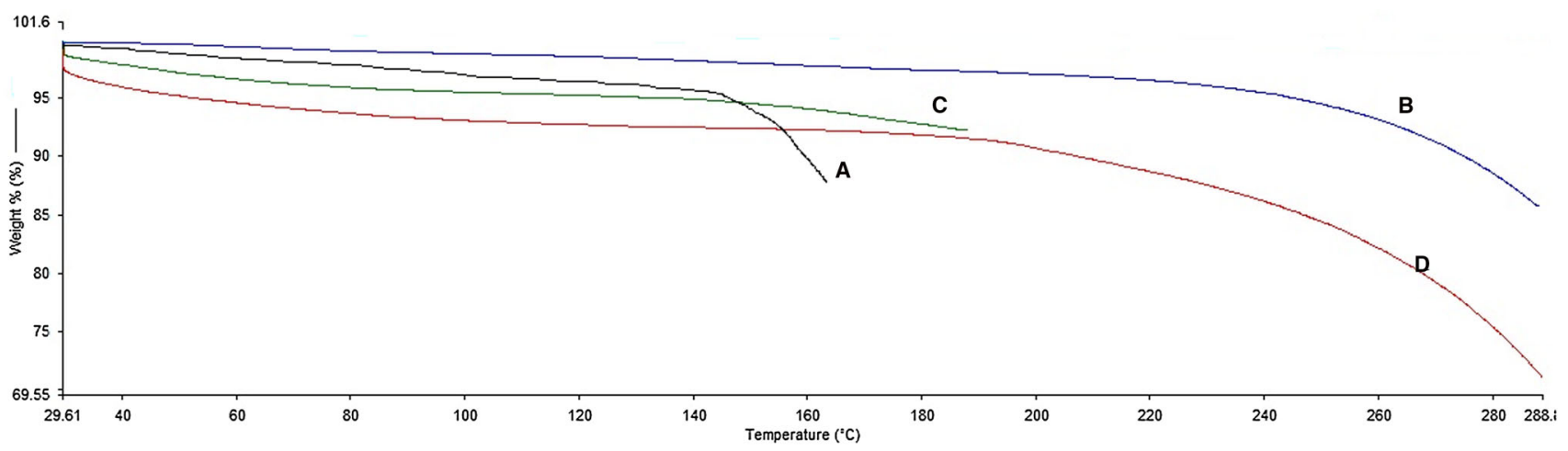

Fig. 3 TGA thermograph of a ketoconazole, b cholesterol, $\mathbf{c}$ optimized formulation F-12, d soya lecithin 


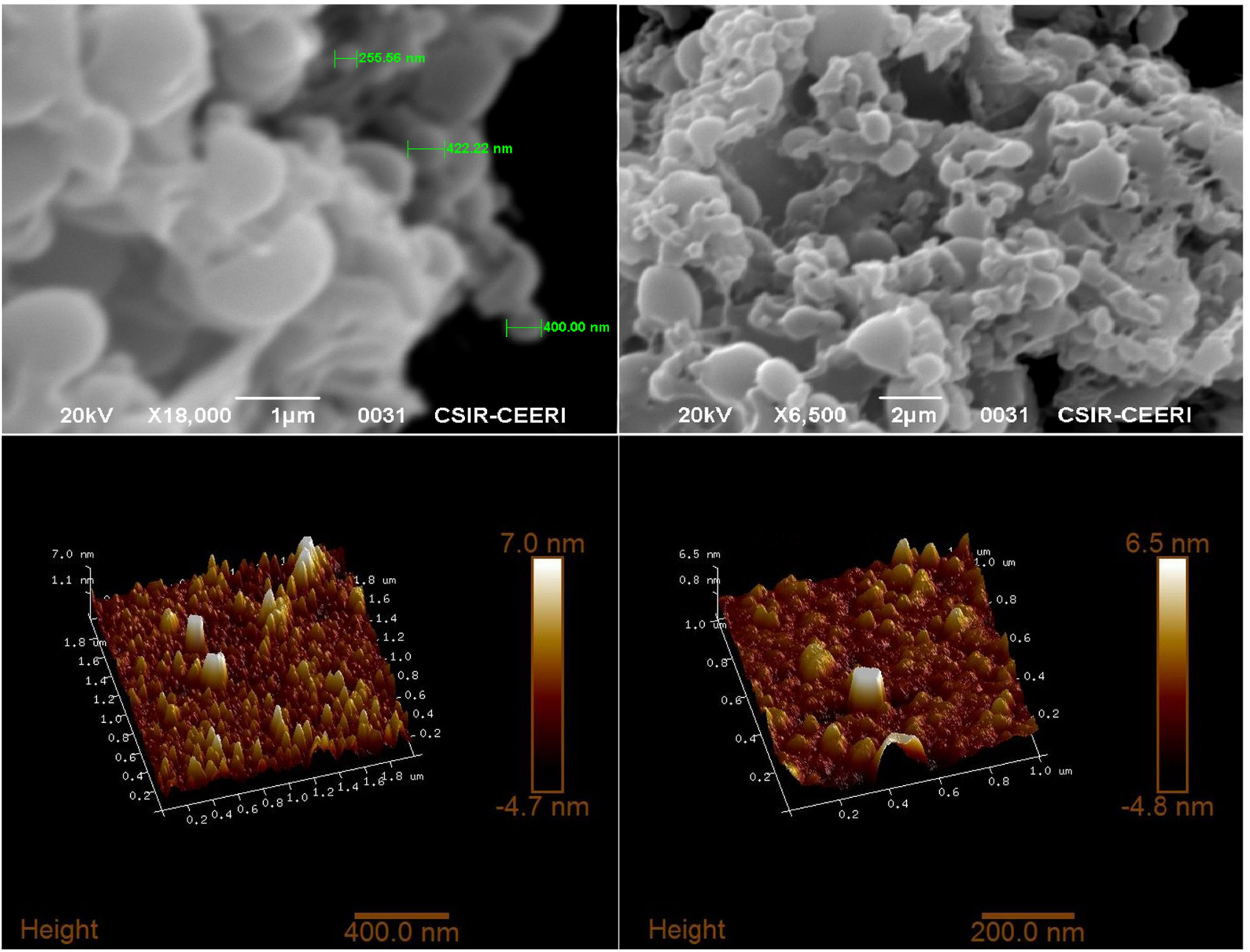

Fig. 4 SEM image of the prepared liposomes at the top showing particle size of 20-200 $\mu \mathrm{m}$ at resolution $\times 6500$ and $\times 65,00$ and AFM images of the optimized formulation at the bottom show their topographical images with the average height of 7.0 and $6.5 \mathrm{~nm}$, respectively

Whereas formulations F4-F6 having the same concentration of soya lecithin and cholesterol, but different penetrations of enhancer stearic acid showed mean particle sizes of $168 \pm 1.6$ to $172 \pm 1.5 \mathrm{~nm}$ with PDIs of $0.333 \pm 0.58$ to $0.412 \pm 0.57$ and zeta potential ranging from $-52 \pm 0.8$ to $-66 \pm 0.5 \mathrm{mV}$, respectively and formulations F7-F9 having the same composition as that of F1F3 and having neem extract showed a mean particle size of $236 \pm 1.2$ to $243 \pm 1.4 \mathrm{~nm}$ with a PDI of $0.245 \pm 0.54$ to $0.365 \pm 0.55$ and zeta potential ranging from $-56 \pm 0.2$ to $-75 \pm 0.5$. Finally, formulations F10-F12 showed the highest encapsulation efficiency and had a mean particle size of $141.6 \pm 1.8 \mathrm{~nm}$ with a PDI of $0.513 \pm 0.67$ and zeta potential of $-45 \pm 0.8$. Whereas in formulations F13 and F14 which is the combination of the same concentration of sorbitol and stearic acid, had mean particle sizes of $237 \pm 1.9$ and $181 \pm 1.3 \mathrm{~nm}$ with PDI of $0.365 \pm 0.53$ and $0.312 \pm 0.58$, zeta potential of $-55 \pm 0.9$ and $-56 \pm 0.4$, respectively, in formulation F15 and F16 sorbitol and stearic acid used in half quantity showed a decrease in particle size when compared to F13 and F14. All these observation reveal that upon increasing the lipid concentration, the particle size also increases. Whereas, the addition of stearic acid instead of sorbitol decreases the particle size (Dodov et al. 2004; Agarwal et al. 2014). Thus, we can say that using an optimum concentration of these ingredients, we can obtain a better formulation such as formulation F12.

\section{Entrapment efficiency}

The entrapment efficiency of the all formulations is depicted in Fig. 5 and Table 2. It was determined to find out the total amount of encapsulate found in the liposome solution by measuring the incorporated drug present in the liposome pellets, after separation of liposomes by centrifugation. The formulations F1-F3 with increased soya lecithin and cholesterol concentrations and having sorbitol, 
Table 2 Characterization table of the prepared liposomes of ketoconazole

\begin{tabular}{lllllll}
\hline Formulations & $\begin{array}{l}\text { \% Entrapment } \\
\text { efficiency }\end{array}$ & $\begin{array}{l}\text { Particle size } \\
(\mathrm{nm})\end{array}$ & $\begin{array}{l}\text { Zeta potential } \\
(\mathrm{mV})\end{array}$ & PDI & $\mathrm{pH}$ Extrudability $\begin{array}{l}\text { Cumulative } \\
\text { release }\end{array}$ & $\begin{array}{l}\text { Spreadability } \\
(\mathrm{cm})\end{array}$ \\
\hline F1 & $41.68 \pm 0.35$ & $188 \pm 1.2$ & $-55 \pm 0.9$ & $0.383 \pm 0.646 .4++$ & $40.68 \pm 0.06$ & 36.5 \\
F2 & $51.1 \pm 1.11$ & $198 \pm 1.0$ & $-62 \pm 0.7$ & $0.356 \pm 0.586 .3+++$ & $47.40 \pm 0.06$ & 25.4 \\
F3 & $52.1 \pm 0.6$ & $131 \pm 1.4$ & $-48 \pm 0.6$ & $0.284 \pm 0.626 .8++$ & $51.59 \pm 1.8$ & 27.3 \\
F4 & $63.8 \pm 0.4$ & $172 \pm 1.5$ & $-66 \pm 0.5$ & $0.382 \pm 0.606 .4+++$ & $58.75 \pm 0.06$ & 49.1 \\
F5 & $65.9 \pm 0.9$ & $171 \pm 1.3$ & $-52 \pm 0.8$ & $0.333 \pm 0.586 .5+++$ & $63.76 \pm$ & 47.3 \\
F6 & $69.7 \pm 1.3$ & $168 \pm 1.6$ & $-63 \pm 0.1$ & $0.412 \pm 0.576 .4+++$ & $68.14 \pm 1.0$ & 28.6 \\
F7 & $48.4 \pm 0.7$ & $237 \pm 1.7$ & $-67 \pm 0.2$ & $0.245 \pm 0.546 .8+++$ & $48.13 \pm 0.6$ & 42.3 \\
F8 & $52.2 \pm 0.8$ & $236 \pm 1.2$ & $-75 \pm 0.5$ & $0.365 \pm 0.556 .3++$ & $46.63 \pm 1.2$ & 46.1 \\
F9 & $55.9 \pm 1.0$ & $243 \pm 1.4$ & $-56 \pm 0.2$ & $0.251 \pm 0.676 .7+++$ & $56.12 \pm 1.2$ & 25.3 \\
F10 & $68.1 \pm 1.1$ & $158 \pm 1.5$ & $-66 \pm 0.1$ & $0.363 \pm 0.566 .4+++$ & $65.60 \pm 0.1$ & 26.7 \\
F11 & $72.1 \pm 0.9$ & $156 \pm 1.6$ & $-53 \pm 0.3$ & $0.488 \pm 0.656 .8+++$ & $68.48 \pm 0.03$ & 24.4 \\
F12 & $88.9 \pm 0.7$ & $141.6 \pm 1.8$ & $-45 \pm 0.8$ & $0.513 \pm 0.676 .5+++$ & $86.38 \pm 0.03$ & 29.6 \\
F13 & $32.8 \pm 0.4$ & $237 \pm 1.9$ & $-55 \pm 0.9$ & $0.365 \pm 0.536 .2++$ & $28.81 \pm 0.06$ & 35.2 \\
F14 & $37.4 \pm 0.5$ & $181 \pm 1.3$ & $-56 \pm 0.4$ & $0.312 \pm 0.586 .1++$ & $32.49 \pm 0.4$ & 33.9 \\
F15 & $53.0 \pm 1.4$ & $147 \pm 1.7$ & $-65 \pm 0.5$ & $0.455 \pm 0.596 .2++$ & $51.85 \pm 0.13$ & 38.1 \\
F16 & $42.9 \pm 0.8$ & $171 \pm 1.6$ & $-69 \pm 0.2$ & $0.387 \pm 0.556 .7++$ & $40.73 \pm 0.03$ & 35.2 \\
\hline
\end{tabular}

* All data are expressed as mean \pm S.D.; $n=3$

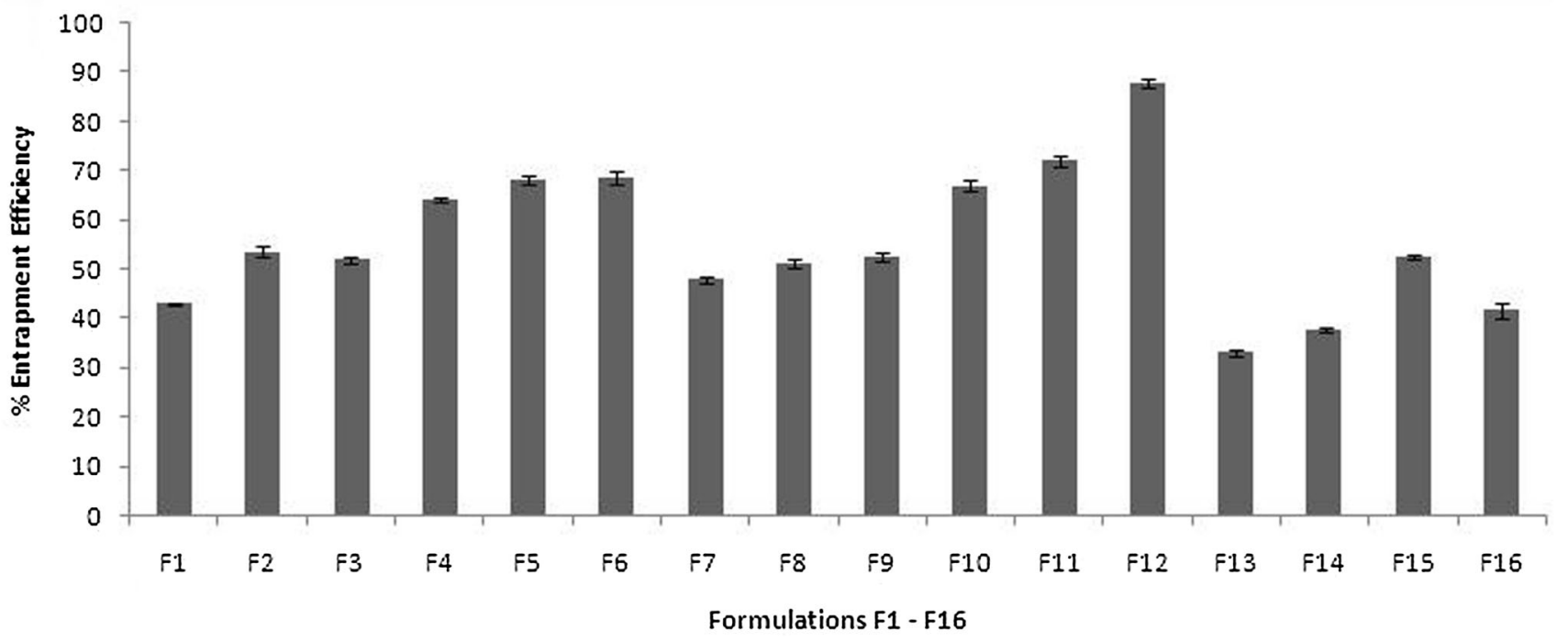

Fig. 5 Entrapment efficiency profiles of different liposomal formulations

encapsulation efficiency was found to be from $43.0 \pm 0.35$ to $52.1 \pm 0.6$, respectively, formulations F4-F6 with increased soya lecithin and cholesterol concentrations and having stearic acid, encapsulation efficiency was found to be from $63.8 \pm 0.4$ to $69.7 \pm 1.3$, respectively. The formulations F7-F9 with increased soya lecithin and cholesterol concentrations and having sorbitol same as that of F1F3 along with neem extract, encapsulation efficiency was found to be from $48.4 \pm 0.7$ to $55.9 \pm 1.0$, respectively. Formulations F10-F12 having stearic acid concentration showed the highest entrapment efficiency of $68.1 \pm 1.1$ to $88.9 \pm 0.7$, whereas in formulation F13 and F14 which is the combination of the same concentration of sorbitol and stearic acid, the entrapment efficiency was $32.8 \pm 0.4$ and $37.4 \pm 0.5$, respectively. In formulations F15 and F16, sorbitol and stearic acid were used in half quantity, which showed a decrease in entrapment efficiency when compared to F13 and F14. Results indicate that the ratio of drug to total lipids or having neem extract concentration showed synergetic effect increased in entrapment efficiency. The 

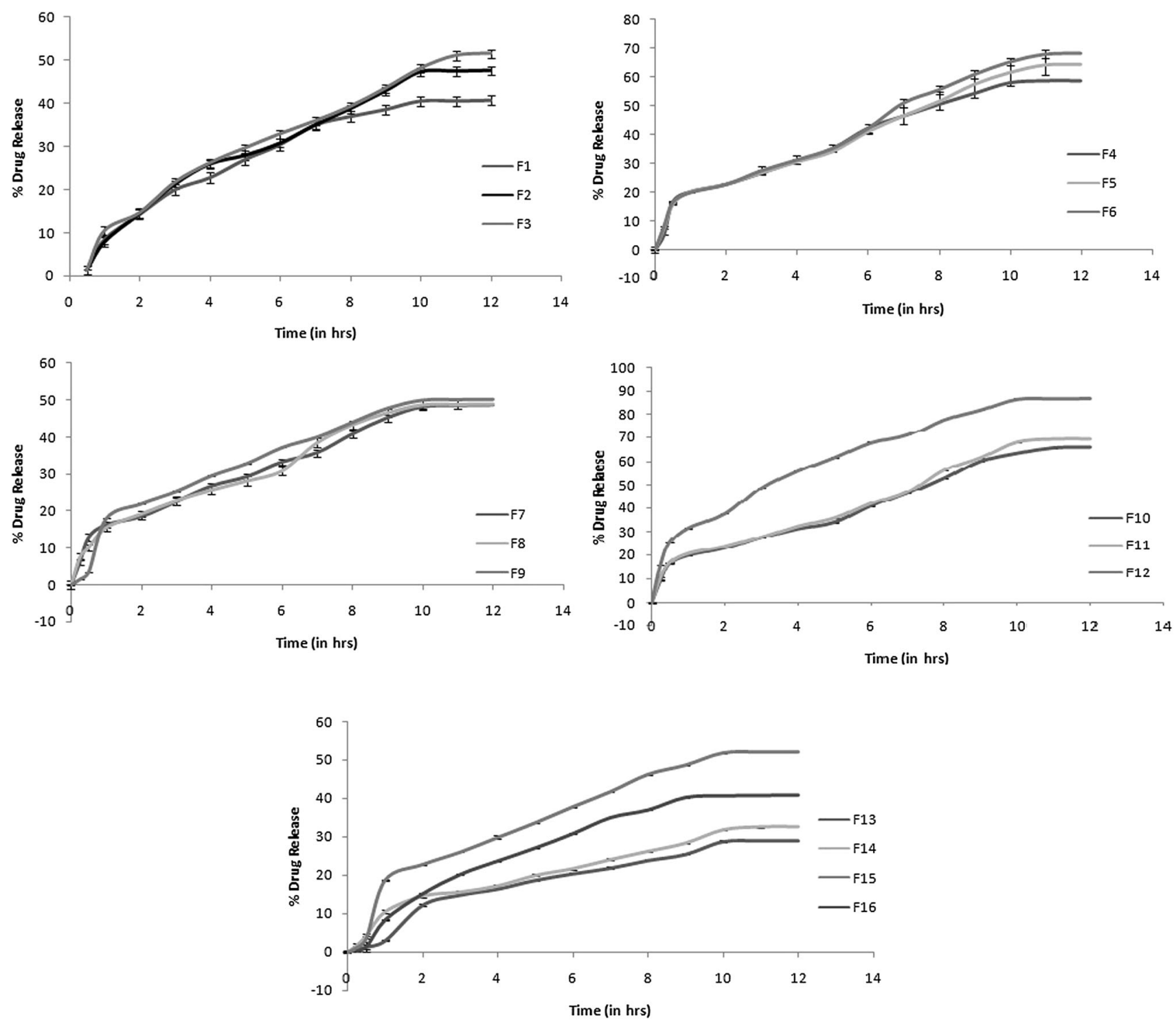

Fig. 6 A cumulative percentage of in vitro drug release of liposomal formulations from F1 to F16

addition of stearic acid despite sorbitol resulted in the entrapment efficiency increasing, when compared to all the other formulations. This factor was further supported by the observation of liposomes formulated by Kaur Indu Pal et al., and others (Yub Harun et al. 2014; Shah and Misra 2004; Vyas and Khar 2007).

\section{Spreadability and extrudability}

The spreadability of the liposomes was determined by the above method and it was found to be in the range between 15.90 and $49.1 \mathrm{~mm}$, which was a sufficient spreading ability for a gel of tropical application.

The extrudability of the formulations is depicted in Table 2. The extrudability of the formulations was found in a range of good to excellent.

\section{Viscosity}

The viscosity of the all the formulations was determined using the Brookfield viscometer at different RPMs 8, 10, 15 and 20. The formulations F3, F6, F12 and F16 show the maximum viscosity.

\section{In vitro drug release}

The results of in vitro drug release are depicted in Fig. 6. The formulations F1-F3 show a release of $40.68 \pm 0.06 \%$ to $51.59 \pm 1.8 \%$ drug release in $12 \mathrm{~h}$, formulations $\mathrm{F} 4-\mathrm{F} 6$ show drug release to be more than $58.75 \pm 0.04 \%$ to $68.14 \pm 1.0 \%$ in $12 \mathrm{~h}$, formulations F7-F9 showed a drug release of $48.13 \pm 0.6 \%$ to $56.12 \pm 1.2 \%$ and formulations F10-F12 have showed a drug release ranging from 


\section{Zero Order}

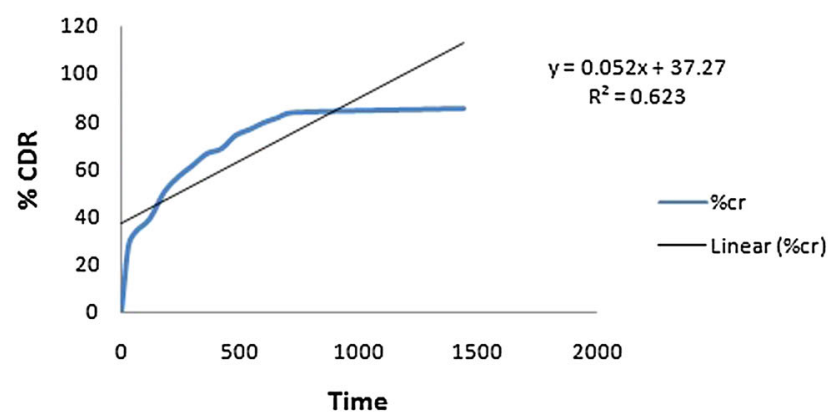

First Order

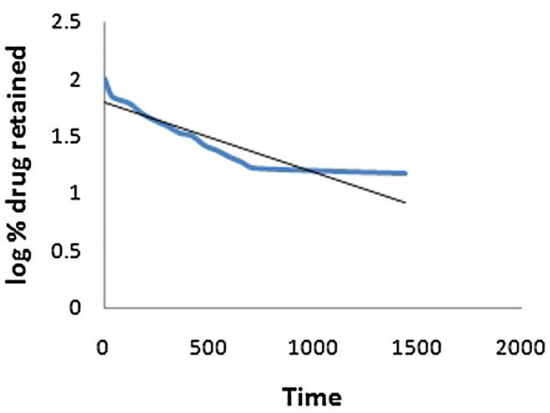

Higuchi

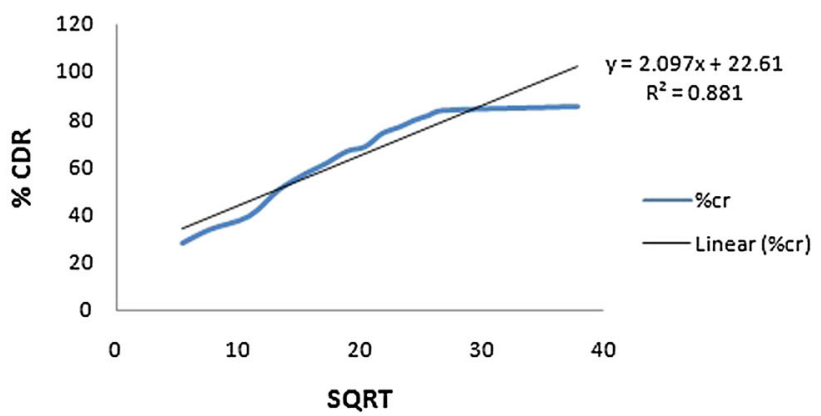

Korsemeyer Peppas Model

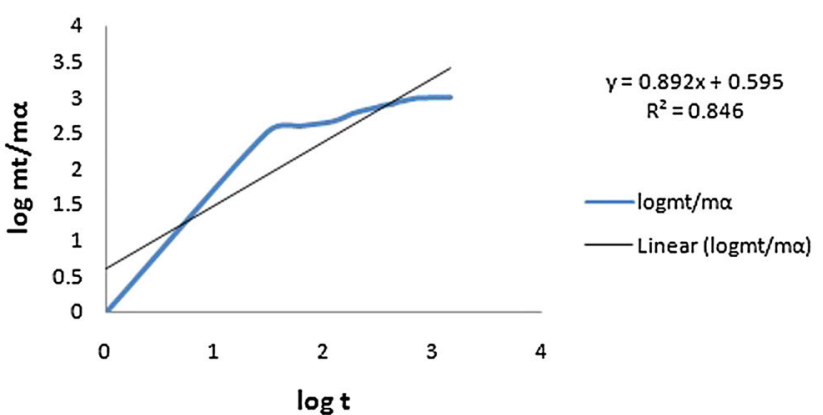

Fig. 7 Drug release kinetics of optimized formulation F12 following Higuchi model

Table 3 Anti-fungal activity of the prepared liposomes of ketoconazole

\begin{tabular}{|c|c|c|c|c|c|c|}
\hline \multirow[t]{2}{*}{ Weight (gm) } & \multicolumn{3}{|c|}{ Aspergillus niger } & \multicolumn{3}{|c|}{ Candida tropicalis } \\
\hline & Control & Drug & $\mathrm{D}+\mathrm{NE}$ & Control & Drug & $\mathrm{D}+\mathrm{NE}$ \\
\hline Empty filter paper & 0.82 & 0.83 & 0.83 & 0.82 & 0.82 & 0.83 \\
\hline After drying weight & 1.70 & 1.42 & 0.86 & 1.91 & 1.53 & 1.29 \\
\hline Net growth of fungus (b-a) & 0.88 & 0.66 & 0.4 & 1.09 & 0.71 & 0.46 \\
\hline Zone of inhibition (mm) & 0 & 5.3 & 8.9 & 0 & 6.2 & 10.2 \\
\hline
\end{tabular}

Control No drug was present, Drug formulation having drug, $D+N E$ formulation having drug and neem extract

$56.12 \pm 1.2 \%$ to $86.38 \pm 0.03 \%$. There was a sharp increase in the drug release after $12 \mathrm{~h}$ for liposome formulations having neem extract formulations F10-F12, respectively. Whereas in formulations F13 and F14, combination of the same concentration of sorbitol and stearic acid showed a release of $28.81 \pm 0.06 \%$ to $32.41 \pm 0.13 \%$. And in formulations F15 and F16, sorbitol and stearic acid were used in half quantity, which showed a release of $51.85 \pm 0.16 \%$ to $40.73 \pm 0.11 \%$, the rate of ketoconazole release increased with the increasing concentration of soya lecithin, cholesterol and stearic acid, due to high efficiency of drug entrapped in polymer matrix. The in vitro drug release data have been analyzed using different mathematical models to know the mechanism of drug release from liposome formulations which are shown in Fig. 7. Based on the highest regression value (R2), which is nearing to unity, liposomal optimized formulations from F12 followed Higuchi model release pattern and showed non-fickian transport mechanism. This suggests that the drug release by swellable polymer matrix through the diffusion controlled mechanism (Table 3).

\section{Stability studies}

The stability study was performed at different temperatures as per the ICH guidelines and (Dave et al. 2010) to identify any possible change in the vesicular structure of liposomes and leaking out of drug from it. Optimized liposome formulation F12 was selected for stability studies. The 


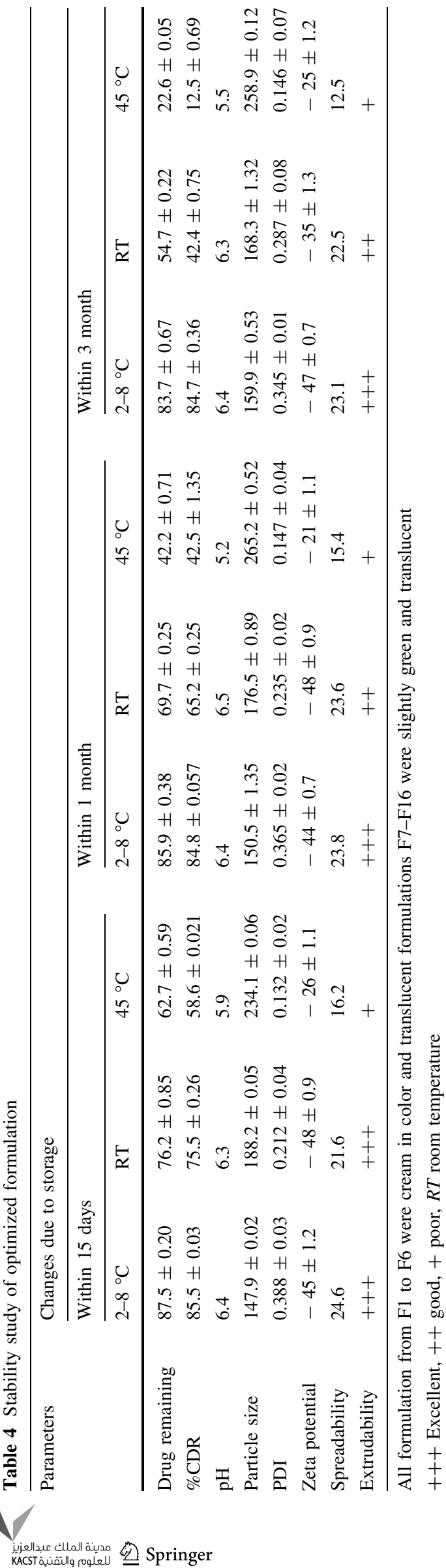

vesicular suspension was kept in sealed vials $(10 \mathrm{ml})$ at refrigerator temperature $\left(4{ }^{\circ} \mathrm{C} / 60 \pm 5 \% \mathrm{RH}\right)$, room temperature $\left(25^{\circ} \mathrm{C} / 60 \pm 5 \% \mathrm{RH}\right)$ and accelerated temperature $\left(40{ }^{\circ} \mathrm{C} / 75 \pm 5 \% \mathrm{RH}\right)$. After 15 days, 1 , and 3 months of the storage at different temperatures, percent entrapment was determined and it was observed that the entrapment efficiency decreases at these time intervals, and entrapment efficiency was seen to decrease with each raise of the temperature, as in 15 days when the entrapment efficiency was determined at different temperatures, at refrigerator temperature $\left(4^{\circ} \mathrm{C} / 60 \pm 5 \% \mathrm{RH}\right)$, room temperature $\left(25{ }^{\circ} \mathrm{C} / 60 \pm 5 \% \mathrm{RH}\right)$ and accelerated temperature $\left(40{ }^{\circ} \mathrm{C} /\right.$ $75 \pm 5 \% \mathrm{RH})$, then it was found to be $87.5 \pm 0.20$, $76.2 \pm 0.85$ and $62.7 \pm 0.59$, respectively, and after 1 month the entrapment efficiency was found to be $85.9 \pm 0.38,69.7 \pm 0.25$ and $42.2 \pm 0.71$, whereas, after 3 months, entrapment efficiency was found to be $83.7 \pm 0.67,54.7 \pm 0.22$ and $22.6 \pm 0.05$, respectively. Along with drug content, sample was also determined for PDI, zeta potential, spreadability, extrudability, $\mathrm{pH}$, viscosity, \% cumulative drug release. Spreadability and extrudability was seen decreasing with the increase of time of storage, but it is to be noted that spreadability and extrudability was seen best at temperature $\left(4{ }^{\circ} \mathrm{C} /\right.$ $60 \pm 5 \% \mathrm{RH})$. No considerable change was seen in PDI at temperature $\left(4{ }^{\circ} \mathrm{C} / 60 \pm 5 \% \mathrm{RH}\right)$ and room temperature $\left(25^{\circ} \mathrm{C} / 60 \pm 5 \% \mathrm{RH}\right)$, particle size was seen increasing with the raise of temperature. After 15 days at refrigerator temperature $\left(4{ }^{\circ} \mathrm{C} / 60 \pm 5 \% \mathrm{RH}\right)$, room temperature $\left(25{ }^{\circ} \mathrm{C} / 60 \pm 5 \% \mathrm{RH}\right)$ and accelerated temperature $\left(40{ }^{\circ} \mathrm{C} /\right.$ $75 \pm 5 \% \mathrm{RH}$ ) particle sizes was found to be $147.9 \pm 0.02$, $188.2 \pm 0.05$ and $234.1 \pm 0.06$, respectively and zeta potential was found to be $-45 \pm 1.2,-48 \pm 0.9$ and $-28 \pm 1.1 \mathrm{mV}$, respectively. After 1 month, particle size was found to be $150.5 \pm 1.35, \quad 176.5 \pm 0.89$ and $265.2 \pm 0.52$, respectively, and zeta potential was found to be $-44 \pm 0.7,-48 \pm 0.9$ and $-21 \pm 1.1 \mathrm{mV}$, respectively, whereas after 3 months, particle size was found to be $159.9 \pm 0.53,168.3 \pm 1.32$ and $258.9 \pm 0.1$ and zeta potential was found to be $-47 \pm 0.7,-35 \pm 1.3$ and $-25 \pm 1.1 \mathrm{mV}$, respectively. \% CDR was also performed at these time intervals and found to be decreased with the raise of temperature and storage time. After 15 days of storage, \% CDR was observed at the temperature that is refrigerator temperature $\left(4{ }^{\circ} \mathrm{C} / 60 \pm 5 \% \mathrm{RH}\right)$, room temperature $\left(25^{\circ} \mathrm{C} / 60 \pm 5 \% \mathrm{RH}\right)$ and accelerated temperature $\left(40{ }^{\circ} \mathrm{C} / 75 \pm 5 \% \mathrm{RH}\right)$ and found to be $85.52 \pm 0.03,75.52 \pm 0.26$ and $58.56 \pm 0.021$, respectively, After 1 month, \% CDR was found to be $84.88 \pm 0.057,65.23 \pm 0.25$ and $42.5 \pm 1.35$, respectively, whereas after 3 months, \% CDR was found to be $84.72 \pm 0.36,42.4 \pm 0.75$ and $12.5 \pm 0.69$, respectively. It was observed that liposomal suspension was more 


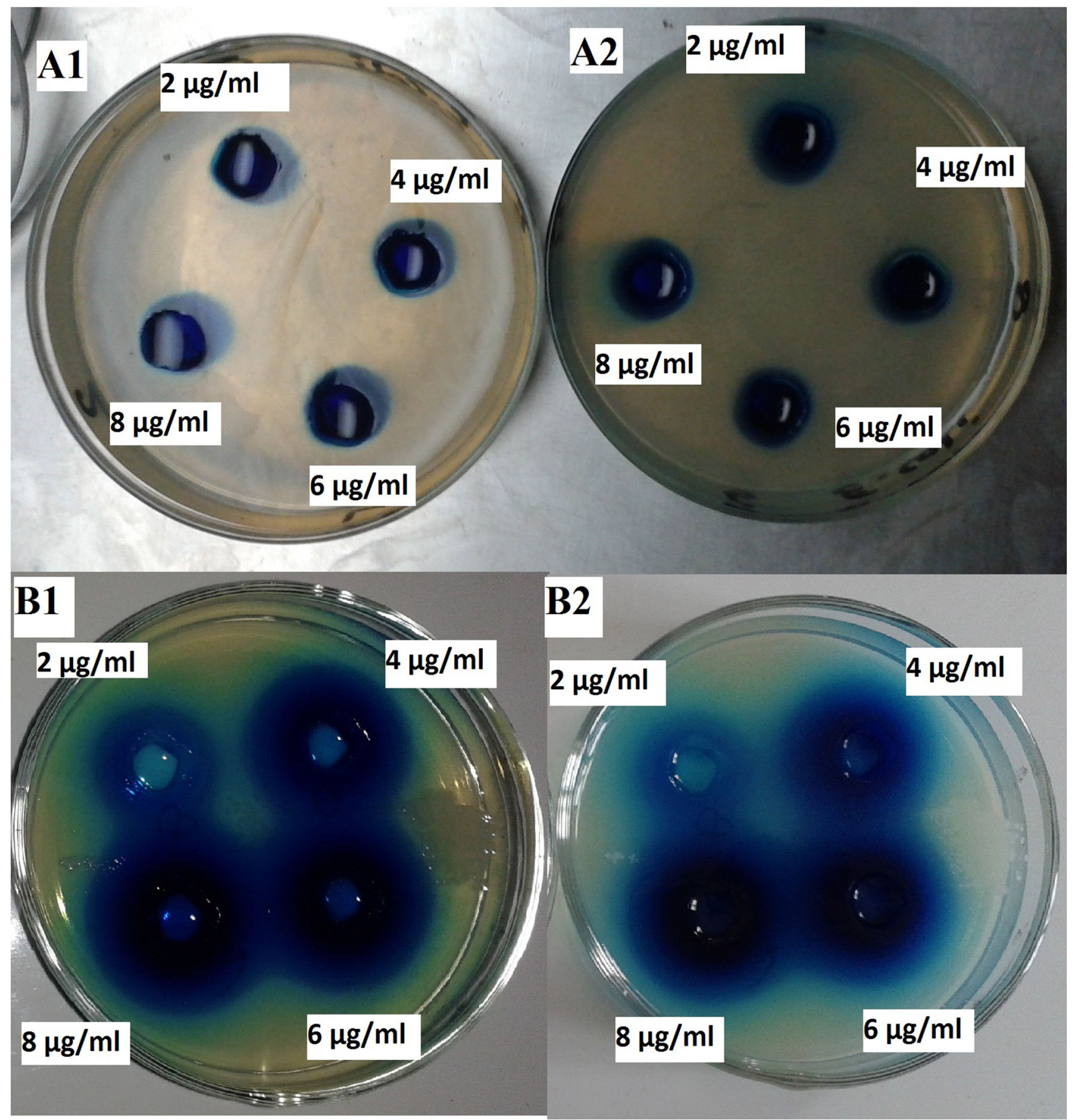

Fig. 8 Anti-microbial susceptibility testing of neem extract on a1 Staphylococcus aureus, a2 E. Coli, b1 neem extract (Staphylococcus aureus), b2 neem extract (E. Coli)

stable at refrigerator temperature, and the results of the studies reveal that no significant change was found in liposomal gel which was stored at refrigerator temperature $\left(4{ }^{\circ} \mathrm{C} / 60 \pm 5 \% \mathrm{RH}\right)$. Stability data of optimized formulation F12 is depicted in Table 4.

\section{Anti-microbial susceptibility test of neem extract}

The result of the anti-microbial efficacy tests is shown in Fig. 8 and Table 3. Neem extract was tested for anti-microbial activity against Staphylococcus aureus and E. coli using ampicillin as standard, which showed good antibacterial activity against gram-positive bacteria 
(Staphylococcus aureus). The formulation showed moderate activity against gram-negative bacteria (E.coli). The study reveals that both of the microorganisms have susceptibility for the neem extract, hence these extracts can be frequently used for the formulation purposes (Syarifah and Izham bin 2014).

\section{Anti-fungal studies}

Optimized formulation was tested against Aspergillus niger (MTCC 8652) and Candida tropicalis (MTCC 9038) by well diffusion method and turbidity method. Three parameters were set. Controlled, where no drug was present, where only the drug was present and (Syarifah and Izham bin 2014; Yub Harun et al. 2014; Shah and Misra 2004; Vyas and Khar 2007) where both drug and neem extract were present. Results of drug along with neem extract were seen to be almost double of the result shown by the formulation, where only drug was present. Hence, results revealed that neem has good efficiency as an antibacterial, and anti-fungal compound. This inference of the study was supported by the work done by Anand Niharika et al. In the present study, it also was concluded that neem extracts and ketoconazole have synergetic effect, as shown in Table 3.

\section{Conclusion}

The results of the study reveal that the herbal formulation of liposome-loaded ketoconazole shows a synergistic effect along with neem extract. The most significant findings of the study were the controlled particle size and zeta potential which shows that the drug in the formulation was stable at prolonged duration of storage and have optimum $\%$ CDR. The anti-fungal activity of the optimized formulation has shown a good therapeutic efficacy towards the treated organism, hence we can conclude that this herbal liposomal gel preparation with neem extract is a significant agent to treat the seborrheic dermatitis.

Acknowledgement This research was carried out at Banasthali University, Rajasthan. The authors would like to thank the Department of Pharmacy of Banasthali University, for their kind support during the work.

\section{Compliance with ethical standards}

Conflict of interest The authors report no conflict of interest.

Open Access This article is distributed under the terms of the Creative Commons Attribution 4.0 International License (http:// creativecommons.org/licenses/by/4.0/), which permits unrestricted use, distribution, and reproduction in any medium, provided you give appropriate credit to the original author(s) and the source, provide a link to the Creative Commons license, and indicate if changes were made.

\section{References}

Agarwal U, Gousia C, Parduman RS, Kumar A, Saxena AK, Vyas SP (2014) RGD-modified anticancer drug containing hybrid nanoparticles for the treatment of 3 integrins overexpressing glioma cells. J Nanosci Lett 1(9):1-8

Aggarwal N, Shinshu G (2012) Preparation and evaluation of antifungal efficacy of griseofulvin loaded deformable membrane vesicles in optimized guinea pig model of Microsporum canisDermatophytosis. Int J Pharm 437:277-287

Ainbinder D, Touitou E (2005) Testosterone ethosomes for enhanced transdermal delivery. J Drug Deliv 12:297-303

Alexopoulouet E, Georgopoulos A, Kagkadis KA (2006) Preparation and characterization of lyophilized liposomes with incorporated quercetin. J Liposome Res 16:17-25

Anand N, Johnson M, Arulsamy A (2010) Antifungal properties of neem (Azadirachta indica) leaves extract to treatment hair dandruff. E-Int Sci Res J 2:244-252

Azmin MN, Florence AT, Handjani RM (1985) The effect of nonionic surfactant vesicle (niosome) entrapment on the absorption and distribution of methotrexate in mice. J Pharm Pharmacol 37(4):237-242

Bangham AD, Horne RW (1964) Negative staining of phospholipids and their structural modification by surface-active agents as observed in the electron microscope. J Mol Biol 8:660-668

Beeravelli S, Mylangam CK, Kolapalli VRM (2016) Factorial design studies of antiretroviral drug-loaded stealth liposomal injectable: pEGylation, lyophilization and pharmacokinetic studies. Appl Nanosci 6:43-60

Benoy BB, Bhabani SN, Chatterjee A (2009) Formulation development and characterization of metronidazole microencapsulated bioadhesive vaginal gel. Int J Pharm Pharm Pract 1(1):240

Betageri GV, Parsons DL (1992) Drug encapsulation and release from multilamellar and unilamellar liposomes. Int $\mathrm{J}$ Pharm 81:235-241

Bhandari R, Kaur IP (2013) A method to prepare solid lipid nanoparticles with improved entrapment. Curr Nanosci 9:3-9

Dave V, Kumar D, Lewis S, Paliwal S (2010) Ethosome for enhanced transdermal drug delivery of aceclofenac. Int J Drug Deliv 2:81-92

Divakar P, Kumar P, Praveen C (2013) Formulation and in vitro evaluation of liposomes containing metformin HCL. Int J Res Pharm Biomed Sci 4(2):479-485

Dmitry V, Schaaf P, Mohwald H (2009) Effective embedding of liposomes into polyelectrolyte multilayered films: the relative importance of lipid-polyelectrolyte and inter polyelectrolyte interactions. RSC Adv 5:1394-1405

Dodov MG, Kumbaradi EF, Calis S (2004) Formulation and characterization of 5- fluorouracil loaded liposomes. Bull Chem Technol Maced 23(1):13-18

Hathout RM, Mansour S, Mortada ND, Guinedi AS (2007) Liposomes as an ocular delivery system for acetazolamide in vitro and in vivo studies. AAPS Pharm Sci Tech 8-1:1

ICH Q1A (R2). (2003) Stability testing guidelines: Stability testing of new drug substances and products. The European agency for the evaluation of medicinal products. CPMP/ICH/2736/99, 4-20

Lasic DD (1990) On the thermodynamic stability of liposomes. J Colloid Interface Sci 140:302-304

Lopes LB, Scarpa MV, Silva GVJ, Rodrigues DC, Santilli CV, Oliveira AG (2004) Studies on the encapsulation of Diclofenac 
in small unilamellar liposomes of soya phosphatidylcholine. Colloids Surf B Biointerfaces 39:151-158

Mohammed Haneefa KP, Shahima Hanan K, Guru Prasad M, Chandini N (2014) Formulation and evaluation of herbal emulgel of pothos scandens linn for burn wound healing activity. J Pharm Sci Res 6(2):63-67

Momo F, Fabris S, Stevanat R (2005) Interaction of fluoxetine with phosphatidylcholine liposomes. Biophys Chem 118(1):15-21

Panigrahi L, Ghosal SK, Pattnaik S, Maharana L, Barik BB (2006) Effect of permeation enhancers on the release and permeation kinetics of lincomycin hydrochloride gel formulations through mouse skin. Indian J Pharm Sci 68:205-211

Rai R, Visht S, Khan A, Saini P (2012) Formulation and evaluation of 5-Flurouracil loaded liposomes. Int J Pharm Phytopharm Res 2(3):222-228

Rosenkrantz W et al (2006) Practical application of topical therapy for allergic, infectious, and seborrheic disorders in small animal practice. J Clin Tech 21:106-116

Sezer AD, Bas AL, Akbuga J (2004) Encapsulation of enrofloxacin in liposomes: preparation and in vitro characterization. J Liposome Res 14(1\&2):77-86

Shah SP, Misra A (2004) Liposomal amikacin dry powder inhaler: effect of fines on in vitro performance. AAPS Pharm Sci 5(4): $1-7$

Shah R, Daniel E, Enzo P, Ian H (2014) Optimization and Stability Assessment of Solid Lipid Nanoparticles using Particle Size and Zeta Potential. J Phys Sci 25-1:59-75
Sharma A (1997) Liposomes in drug delivery: progress and limitations. Int J Pharm 154:123-140

Singh A, Vengurlekar P, Rathod S (2014) Design, development and characterization of liposomal neem gel. Int J Pharm Sci Res 5:140-148

Srisombat N, Jeeratikorn E, Chuwit E, Porntip B, Sakdanai S, Photchanart T (2005) Skin irritation test of curcuminoids facial mask containing chitosan as a binder. Silpakorn Univ J 5(1-2):140-147

Syarifah MHD, Izham bin AR (2014) Antimicrobial activity of methanolic neem extract on wound infection bacteria. International conference on biological, chemical and environmental sciences (BCES-2014), pp 72-75

Uchegbu IF, Vyas SP (1998) Non-ionic surfactant based vesicles (niosomes) in drug delivery. Int J Pharm 72:33-70

Vyas SP, Khar RK (2007) Targeted \& controlled drug delivery: novel carrier system. CBS Publishers and Distributors, New Delhi, pp 173-248

Yub Harun N, Afzal MT, Azizan MT (2014) TGA analysis of rubber seed kernel. Int J Eng 3(6):639-652

\section{Publisher's Note}

Springer Nature remains neutral with regard to jurisdictional claims in published maps and institutional affiliations. 